\title{
The dialogic construction of patient involvement in patient-centred neurorehabilitation
}

\author{
Jannie Uhre \\ Department of Communication and Arts, Roskilde University, Denmark
}

\begin{abstract}
This paper explores how the practice of patient involvement in neurorehabilitation is constructed in tension-riddled professional narratives. I adopt dialogic communication theory to focus on how involvement is constructed across different roles and voices. My analysis is based on an action research project that uses a dialogical communication perspective and participatory methods to explore patient-centred care through the eyes of healthcare professionals. I argue that patient involvement is constructed as a demanding process that requires memory, presence, communicative abilities and temporal understanding of personal needs. These requirements are not explicit in the situated institutionalized practices. As well, I show how the available involvement strategies are laced with taken for granted characteristics, which fall short in the situation that arises when patients do not have the ability to participate or play the role of an active patient. The findings in this paper contribute to the growing literature on patient-centred healthcare by empirically investigating how the discursive configuration of patient, health professional and institutional practices intertwine in producing certain inherent expectations, habits and taken for granted perspectives in care delivery. I also suggest that the findings can usefully be incorporated into patient-centred care design and organizational strategies in order to take into account both the patient, relatives and healthcare professionals as vital for creating a patient-centred practice, organization and professional environment.
\end{abstract}

\section{Introduction}

The definition of patient-centred care is fluid. There is talk of a discursive turn away from paternalistic medical authority. However, what we are turning to is a little harder to define. In both practice and research, it is variously labelled person-centred, person-focused and patient-centred care. $^{1-3}$ The diverse interpretations range

Correspondence: Jannie Uhre, Department of Communication and Arts, Roskilde University, Univeristetsvej 1, 4000 Roskilde, Denmark.

E-mail: janniekristine@gmail.com

Key words: Patient involvement; Patient-centred care; Dialogic communication; Neurorehabilitation.

Conflict of interest: the author declares no potential conflict of interest.

Funding: funding from Region of Zealand, Denmark.

Received for publication: 30 August 2018.

Revision received: 19 December 2018.

Accepted for publication: 19 December 2018

This work is licensed under a Creative Commons Attribution NonCommercial 4.0 License (CC BY-NC 4.0).

C Copyright J.K. Hoffmeyer Uhre, 2018

Licensee PAGEPress, Italy

Qualitative Research in Medicine \& Healthcare 2018; 2:165-175

doi:10.4081/qrmh.2018.7792 from being responsive to the individual needs of patients in clinical decision making to actively involving patients in the decision-making process. ${ }^{4}$ Some describe patientcentredness and involvement as a goal for healthcare delivery while others construct it as a means to improve healthcare. ${ }^{4,5}$ The confusion surrounding the meaning of patient-centred care leaves a gap between values and practice. ${ }^{3,4}$ This gap is partially created by the different ways the concept of patient-centredness and involvement are used and adapted to fit in with existing institutional priorities like organisational or financial efficiency. ${ }^{4}$ The lack of consistency in the ascription of meaning to the concept makes the practice of involvement and patient-centred care ambiguous. ${ }^{4,5}$ In this paper I aim to show how this ambiguity becomes practice whereby healthcare professionals both deviate from, and conform to, institutional guidelines and also reconcile the conflicting logics, which lace the involvement practices that are available to them.

I adopt a dialogical communication perspective inspired by Mikael Bakhtin whereby meanings are understood to be produced in the interplay between different voices. Voices are in this paper a theoretical concept encapsulating how perspectives, values, habits, ideologies etc. are negotiated and construct a multivocal, unstable and unfinalizable unity of meaning..$^{6-8}$ Through a dialogic lens, I look at how involvement is constructed in narratives of health professionals. I draw on a social constructionist view of communication as constitutive of social reality, including knowledge, identities and social relations ${ }^{6,9}$ and narratives as a communicative site where we construct and ascribe meaning to practice. ${ }^{7,10} \mathrm{I}$ examine how the interplay of different voices ascribe meaning to 
situated practices of involvement and form identities tied to the enactment of involvement in a healthcare setting. My guiding research questions in this paper are: How is patient involvement constructed between different voices representing organizational habits and values, patient-centred values, personal experiences and more? What does this construction of practice require of the patient?

The purpose is to gain insight into how patient ideals and expectations towards the patients are negotiated in professional practices of involvement when the patient cannot meet the inherent demands. In the paper, I examine the articulation of challenging involvement processes in the field of neurorehabilitation. I look at how the patient and healthcare professional are constructed in the involvement practice and how each professional doubt or choice is based on a negotiation of voices in practice. With respect to contributing to practice, the aim of the analysis is to further sensitivity towards the habits and taken for granted notions that might hinder a process of involvement that, along holistic lines, is personally tailored to the needs and values of the individual patient. With respect to contributing to the research literature, the aim with the analysis is to show how the discursive ambiguity of $p a-$ tient-centred care has consequences for the construction of and legitimization of patient-centred involvement practices. Furthermore, this paper contributes to research on patient-centred healthcare and dialogical health research by focusing on how healthcare professionals dialogically construct patient involvement in relation to patients suffering the effects of traumatic brain injury.

The paper is structured as follows. First, I present a short review of literature that outlines some of the discrepancies in the discursive movement towards patient-centred care and the production of patient involvement practices. I then outline the dialogical framework and present the methods used to co-produce the professional narratives that form the empirical material. This is followed by the dialogical analysis of two professional narratives. Finally, I discuss analytical results with respect to both the existing research literature and the field of practice.

\section{What is patient-centred care and involvement?}

Patient-centred care and involvement have been high on the political agenda for the last twenty years both in Europe and in Denmark. ${ }^{11-14}$ In line with this development, there is a growing body of research describing the turn towards patient-centred care and how multiple interpretations of the concepts flourish having consequences for patients and the healthcare sector as a whole..$^{13-15}$

Several studies have shown the discursive development where patients are constructed in the tension between being a service consumer and a responsible active patient. ${ }^{13-16}$ Explorations of governmentality perspectives have shown how these different health strategies deploy different technologies of agency and performance. ${ }^{15}$ This discursive figure becomes a patient role infused with ac- countability and moral tones that emphasizes the responsibility of the individual patient for contributing to the quality of their own healthcare. ${ }^{9,17}$ Studies show how a patient-centred perspective is merged with existing perspectives in healthcare institutions. ${ }^{18,19}$ This might be beneficial in some cases, but in other cases, the result is overlapping and contradictory ideologies in play at the point of care delivery. This creates discrepancies between public, political, and professional expectations when the organizational capability to adapt or transform does not measure up. ${ }^{18,19}$

Some shared markers of the patient-centred agenda are a focus on the patient perspective and context when making decisions on treatment plans. There is also a core focus on communication with regards to reaching a shared understanding and involving the patient in determining the right care option. ${ }^{4,20}$ The process of delivering and producing patient-centred care is based on the encounter between the patient (and next of kin) and the health professional. ${ }^{19}$ There has been a significant amount of studies focusing on patient stories and unravelling the patient position in these encounters. ${ }^{20,21}$ These studies are important to understand the relational power that is inherent to the encounter. They often involve a critique of the health professionals' abilities to practice care centred around the patients' wishes and needs. ${ }^{20-22}$

In communication studies on patient-centred care, there has been a focus on shared decision making in the relationship between patient and healthcare professionals. ${ }^{4,21} \mathrm{Sev}$ eral studies analyse the communicative tensions that can arise between patients' and healthcare professionals' priorities in the delivery and decision-making processes in patient-centred healthcare. ${ }^{20,21}$ In these encounters, slight differences in the communicative practices can distinguish participatory efforts from paternalistic practice. ${ }^{17,23}$ The expert role of the healthcare professional creates a communicative situation where his/her knowledge and interpretation of events and symptoms are privileged. ${ }^{23,24}$ In this line of research, the shared nature of decision-making becomes a parameter of patient-centred communicative practice. These studies assume that the patient masters the communicative skills that it takes to participate in the shared decision-making in communicative practices. ${ }^{17,25}$ Other underlying assumptions connected to the patient-centred production of care are cognitive abilities like memory, processual thinking and information processing. ${ }^{17,25}$

One study reviewed literature to define patient-centredness and patient involvement in stroke-care. Among other conclusions, they found communication to be both an important barrier to, and a vital component in, patientcentred practice. ${ }^{20}$ For stroke victims as well as patients with traumatic brain injuries, communication can be complex. Injury to the brain often leave patients with communicative impairment that becomes an inclusion or exclusion mechanism in patient-involvement. ${ }^{20,25}$ The literature shows that health professionals have a tendency 
to ignore the patient with communicative impairment and instead orient their efforts towards the next of kin..$^{20,25}$ The specific difficulty in practising patient-centeredness in relation to stroke victims is determining the individual needs of the patients within the process of regaining consciousness, motor-function, memory and other cognitive abilities. Literature on the subject suggests alternative methods of engaging the patient with eye contact, respectful listening and in-depth explanations in regards to activities and prognosis. ${ }^{20}$

Involvement is depicted as a practice that requires the patient to participate, communicate and understand their personal needs to be involved in the health process..$^{25}$ These requirements prevent some patients from being involved and including their perspective in collaborative decision-making about the treatment process. ${ }^{20,25} \mathrm{~A}$ study by Lord and Gale (2014) shows how patient-centredness and involvement were constructed as a core value in the strategic views on designing service delivery but were difficult to articulate into practice. The study shows that organizational habits, the professional knowledge system, and institutional structures formed barriers to a patient-centred way of thinking and practice development. One of the findings of the study is that patient knowledge or subjective experience is devalued in the process of objectifying care delivery. ${ }^{4}$ This problematizes how different knowledge forms vary in status in the health system. They found that the professional knowledge forms were favoured on the strategic level of the organizations. They also found that this were more pronounced when decisions were made at an distance from the everyday practices of care delivery. ${ }^{4}$ A study by Mjølstad et al. (2013) shows how accumulated personal history gathered by general practitioners does not translate into rehabilitation activities. The authors found that the institutional voice of medicine has a tendency to override the patient's personal narrative when planning rehabilitation. ${ }^{3}$ This happens even though the health professionals want to practise patient-centred care, and to some extent, think that they are doing so.

A recent study investigates how patients are constructed in a Danish communication program. ${ }^{26}$ This study shows how six patient figures are formed in the communication program and how they shape the self-understanding of healthcare institutions. Pors ${ }^{26}$ (2016) shows how health communication efforts create a patient role suspended in a tension between market and care perspectives and these different rationales create an organization that interweaves standardized processes with individualized care. These patient figures all have a common understanding of an active and information-seeking patient. The patients are seen as resources in the organizational effort to improve quality through patient-centred care. The study also outlines the absence of the patient who is inactive/passive and refuses information. One of the interesting perspectives in this study is that Pors finds that there is no language for describing the inactive or inca- pable patient. This leaves a void for the patient who cannot fill this role. This is also demonstrated in the professional narratives presented in this paper.

To sum up, studies show that policy, strategy and intervention can be designed to promote patient-centred involvement but this does not necessarily translate into care delivery in practice. ${ }^{4,20}$ The barriers identified are linked to the lack of a common definition of patient-centred care and practice. Patient-centred practice appears to be a professional ideal more than an clinical reality. ${ }^{3}$ In this paper I look at how involvement is translated into practice and how these practices become challenging when collaborating with patients suffering effects of traumatic brain injurie that prevent them from filling the role of the normal and active participants in their own treatment process. ${ }^{17,24,25}$

\section{Analytical framework}

\section{A dialogical communication approach}

In this paper, I embrace the notion of a narrative kind of knowledge. ${ }^{10,27,28}$ I see narratives as chains of past events organized to construct meaning in relation to the events but equally in the current relational context. In this sense the narratives are performative in creating understandings of our past and meaning in the present. ${ }^{7,28}$ Many narrative studies in healthcare present the clinical communication encounter and critically examine how patients and healthcare professionals construct different types of narratives.$^{29-31}$ The focus is primarily on the patients' narratives as a source of knowledge. ${ }^{10,31}$ In this paper, I choose to look at the narratives of healthcare professionals to show how the health professionals navigate contradicting perspectives in patient-centred healthcare. I adopt a discourse analytical approach building on dialogical communication theory developed by $\operatorname{Baxter}^{6}$ (2011) and Phillips $^{8}$ (2011). The branch of dialogic communication theory I draw on in this paper stresses the discursive nature of professional narratives and their constitutive function in ascribing meaning to the world. ${ }^{7}$ With this dialogic perspective, I focus on the different and often contradicting voices that make up the narratives. This builds on the basic principle that narratives are a dialogical expansive genre $^{32}$ and a way to organize and ascribe meaning to the world and our different identities in the world. ${ }^{10,28}$ Dialogue in this perspective is viewed as the relational negotiation of different voices in the process of ascribing meaning to the world. ${ }^{6,8,33}$ In this perspective, narratives help shape practice through the meanings they ascribe to practices including involvement and patient-centered care. I see the narratives of healthcare professionals as a valuable source of innovative knowledge that stems not just from one but from several encounters with patients. ${ }^{10,34} \mathrm{I}$ find that their perspective can be enlightening and provide key information into how patient-centred practices can be improved. ${ }^{19,34}$ This is founded on a premise that health professionals through narratives make sense, construct and conceptualize patient-centred care and involvement 
in relation to the patient and colleagues as an integral part of their everyday professional practice, shaping what they do as they do it. ${ }^{7,28,34}$

The branch of dialogic communication theory that I apply in this paper draws on Bakhtin's dialogue theory to examine the production of meaning as it emerges through the interplay between multiple voices. ${ }^{8,33}$ In other words, all communication is viewed as dialogic as meanings are formed within and across voices. ${ }^{6,8}$ The voices are not understood as the individual's uttered speech. Inspired by Bakhtin, a voice is conceptualized as a perspective, ideology or discourse that interpenetrates an utterance and constructs a multivocal, unstable and unfinalizable unity of meaning. ${ }^{6.8} \mathrm{~A}$ dialogic communication analysis captures the multivocal negotiation of meaning in communication. The dialogical communication approach I follow in this paper builds on the social constructionist premise that social knowledge, subject positions and actions are constructed in discourse. ${ }^{9,35}$ Discourse is seen as a historically, culturally and geographically situated perspective from which meaning is ascribed to the world. ${ }^{8,35}$ In a Bakhtinian terminology, communication as dialogue is constitutive for the continuous construction of identities through the interplay of different voices. ${ }^{8}$ The dialogical approach I apply in this paper offers an analytical lens that view the relational co-construct of ourselves and others in the meaning making process. ${ }^{6,8}$ In this perspective I also view disability as a dialogical construct constituted in communication (discourse). This entails that the functional and/or cognitive impairments suffered by patient with a traumatic brain injurie are not fixed medical categories (if such exist) but gain their meaning in different social context. ${ }^{5,24,36}$ The social context of this study is a neurorehabilitation process situated in the institutionalized healthcare settings in Denmark. The dialogical approach is a way to see how contradicting discourses (voices) are at play as the disabled patient and the health professional roles are constructed interdependently ${ }^{24}$ in the situated institutionalised practise of patient involvement in patientcentred care.

My analytical focus inspired by Bakhtin homes in on the utterance as the communicative site of this interplay between voices. ${ }^{7}$ The utterance is a broad definition that spans from a single sentence to a longer text. In this paper, the utterances that I examine are two professional narratives that deal with the experience of involving a patient suffering effects of a traumatic brain injury. In each utterance, multiple and conflicting knowledge forms, rationales and perspectives come together to form an unstable unity. To help identify the different voices articulated, I draw on Baxter's analytical framework ${ }^{6,7}$ to look for discursive markers and discursive micro practices that potentially signify discursive counterpoints in the narratives. Specifically, I focus on discursive markers present in the synchronic interplay between co-present voices that intersect in each of the narratives. ${ }^{6}$ In the narratives pre- sented, the synchronic interplay between voices can be described as polemic. The polemic interplay is characterized by a struggle between conflicting discursive positions. Features of a polemic struggle are among others the discursive markers countering and entertaining. ${ }^{6}$ Countering marks a discursive counterpoint by replacing an expected discursive position with an alternative one. Entertaining marks a polemic interplay where multiple possible discursive positions are possible. In connection to the two discursive markers, there are a long list of discursive micro practices signified by different lexical choices. ${ }^{6}$ In my analysis of the narratives, each micro practice identified will be explained in context. To further explore how meanings are produced in the interplay between different voices I look at the relations between the voices. This means I look at how dominant the voices representing a more normalized perspectives and more marginalized voices intersect in the construction of meaning. ${ }^{8}$

In the narratives there are several voices infusing the construction of involvement, the role of the patient and role of professional. The multivoiced negotiation forms tension-filled narratives that I will analyse by addressing the questions: What voices are articulated in construction of involvement in neurorehabilitation practices with complex patients? What identities and expectations are constructed in the different voices animating the practice of involvement?

\section{Materials and Methods}

\section{Action research and workshop design}

The empirical material I analyse in this paper has been produced as part of an action research project. The action research project aimed to produce knowledge about patient-centred care in neurorehabilitation with a focus on cross-sectorial teamwork and patient involvement. The project involved healthcare professionals from both an outpatient hospital unit in Region Zealand in Denmark and some of their cross-sectorial colleagues from the surrounding municipalities. The project was designed collaboratively in an ongoing decision-making process between the participants and researcher. The action research project was built on the ideal of participation being voluntary and participants being given the role as co-determinants throughout the process. ${ }^{37}$ I (the researcher) initially invited the participants personally and they were chosen because of their work in cross-sectorial collaborations within the field of neurorehabilitation.

The action research project involved several different collaborative and qualitative research efforts. One of the key elements of the project was three dialogical workshops held in the autumn of 2015. In this paper, I draw on data from the first of three workshops. Eight healthprofessionals from different municipalities and hospital services participated. The theme of the workshop was 
the challenge of patient involvement in neurorehabilitation. It was chosen in collaboration with the workshop participants and reflected a subject matter that was both relevant and meaningful for the participants to work with and develop. The workshop design and the facilitating role in the workshop were delegated to the researcher (author).

In the workshop, the participants and I (the researcher) co-produced knowledge about problems, practices, quarrels and values of patient involvement based on the participants' joint experiences of working with patients who had suffered a traumatic brain injury. The workshop was based on narrative exercises. The exercises were designed specifically for the workshop and drew on empirical material collected prior to the workshop. These data consisted of interviews and observations with participants, their cross-sectorial colleagues and patients suffering the effects of traumatic brain injury The workshops were dialogical in the sense that all the narrative exercises were built on dialogical principles inspired by Mikhail Bakhtin. Bakhtin saw difference as a force of change because he theorized that meaning is produced in the interplay between different perspectives (voices) ${ }^{8}$ In the workshop design this principle was directly adapted as the participants were encouraged to explore their differences and inquire into each others' motives and understandings of the practice of involvement. The design was focused on the participants' own choice of subjects as well their choice of narratives. This means that the narratives presented in this paper were produced in conversation and not limited to a rigid framework of questions. ${ }^{7}$ The participatory narrative focus gave the health professionals a space to share their perspectives on patient involvement and engage in co-producing new perspectives on various situations that challenged their own perceptions of their professional practices. The narratives presented in this paper were selected as they prompt multivoiced co-reflection between the participants within the workshop. They also reflect some of the core problems or challenges described by the healthcare professionals during the action research project. To preserve the anonymity of the participants I have altered identifying details in the empirical excerpts. The interaction in the workshop was audio recorded and transcribed. The analytical focus is to unfold the tension that the narrative holds within itself to show how meaning is ascribed to situated practices of involvement and how professional navigate contradicting perspectives on patientcentred care in their everyday work routines.

My motive for designing a workshop with a narrative focus was a conviction that narrative abilities can be learned. ${ }^{38}$ This is anchored in two perspectives. One is the notion of dialogical wisdom, drawing on Barge and Little (2002), ${ }^{39}$ understood as a sensitivity towards positions and opportunities in an encounter. The other is the notion of narrative competence, drawing on Frank (1998), ${ }^{27}$ that nurtures the ability to see patterns in life stories. Collectively, the workshop participants and I found these perspectives to be relevant especially when it comes to patients who are suffering complex and life changing illness. ${ }^{3}$

The purpose of the workshop was not to design a solution but to enable collective reflection on problems that were shared between participants across their different contexts. Our co-inquiry focused on both practical aspects of patient involvement and the participants' reflections on how their practices mirrored or diverted from the situated ideals of involving a patient.

This study has limitations in the small number of participants and their occupations. The results are not generalizable or representational in the statistical sense. Instead, the results show tensions present within the fields of neurorehabilitation and patient involvement that may be recognizable to other health professionals within the field of practice. ${ }^{40}$ This recognition gives the results applicability. Qua this applicability, qualitative and participatory research can, in my opinion, serve as a powerful change-agent in the turn towards patient-centred care delivery and quality improvements for both patient and professionals. ${ }^{10,19,34}$

\section{Analysing the practice of involvement with complex patients}

The following analysis aims to show how involvement is ascribed meaning in two different professional narratives and examine how professionals negotiate and reconcile the discursive ambiguity in patient-centred healthcare. All the narratives describe situations where the practice of involvement became a professional challenge. The narratives are based on professional experiences in the systemic context of cross-sectoral coordination and neuro-rehabilitation work in Denmark.

Each of the professional narratives contributes with different perspectives on the dialogic construction of involvement and demonstrates how the construction of the patient and the professional is an integral part of the situated involvement practices. The narratives are told from a professional perspective and the voices that might have been introduced by e.g. patients or managers are therefore not present in excerpts. The analysis contributes by investigating how involvement is constructed from a professional perspective. Further, it reflects on practical limits of patient involvement in patient-centred neurorehabilitation that are constructed in the discrepancies between contradicting voices in practise.

\section{Patient involvement - But he has some cognitive injuries}

The following excerpt unfolds a professional narrative that describes the process of involvement for a young man. The example shows how the apparently normal young man, through his reduced ability to remember, is constructed as unable to participate appropriately in the institutionalized practice of involvement. The context of the narrative is the municipal health and social care sys- 
tem. In Denmark, the municipal system provides help and services for citizens who are unable to provide for themselves financially and/or socially. In this case, the young man is recovering from a traffic accident in which he acquired a brain injury. Due to his injuries, the process of involving the young man is a professional challenge:

Ursula (municipality): "This young guy is apparently healthy and anyone would say, 'you're fine'. But he has some cognitive injuries and there's some damage to his frontal lobe, but he fools both us, himself and others because of his seemingly normal behaviour. And he doesn't do it on purpose. But over time, we can see that all's not well. But when it comes to involvement. Actually, I have to involve him. But I quickly find out, that it doesn't work because he has a memory like a sieve. So gradually the involved party becomes his mother. Because she also notices that it isn't completely coherent. So this leads to him getting less and less involved because I have to communicate everything with her. And I sometimes have a moral struggle like, what am I doing? And if I were to follow the law, then I would have broken it 17 times. But to benefit his case and to benefit his situation and to make the system work for him, we have pushed him more and more onto the sideline." (Quote from workshop 1)

The first four sentences set the scene for the professional dilemma. They do so by constructing the young man as abnormal through entertaining a polemic discursive context. ${ }^{6}$ In the intro, two voices are entertained in dialogue - the voice of normality and the voice of neurohealth professionalism. The voice of normality draws on a wider discursive understanding of being normal. This discursive resource is introduced through a naturalization practice. ${ }^{6}$ This micro practise enters the voice of normality into the narrative as a transparent category representing a given way of being a patient in the systemic context. The voice of normality serves as a backdrop from which the boy is constructed as an opposite. The young man is introduced as "healthy" and "seemingly normal", but he fools everybody. The words "normal" and "healthy" in conjunction with words like "apparently" and "seemingly" make the statements about his appearance more tempered and indicate other dialogic alternatives. The alternative in this case being that the young man diverges from "normal" due to his injuries. Through the mention of neuro-professional concepts such as "cognitive injuries" and damage "to his frontal lobe", the voice of neuro-health professionalism introduces a knowledge form that is expressed in language, which conceptualizes the young man's divergence. This voice introduces an understanding of his injuries by explaining how "he doesn't do it on purpose". The voices of normality and neuro-professionalism align in polemic interplay to co-construct a position where the young man diverges from the normal as a neuro-impaired patient. In the dialogic construction of the other - in this narrative, the young man - the dialogic self or in this case, an " $u s$ " is constructed as a counterpart. The young man in this story requires both care and diligence from " $u s$ ", the professionals, as he unintentionally "fools both us, himself and others". This constructs a professional us that sees the divergence and the injuries, but only "over time". The temporal hesitation stresses both the complexity of the injuries but also hints at a vulnerability in professional practice. The vulnerability in this case is that even the neuro-professional need time to discover and understand how an injury to the brain surfaces and unfolds in the individual patient. ${ }^{5,24}$

When the contexts and positions are in place, the narrative shifts focus to the practice of involvement. The situated meaning of involvement is negotiated against the backdrop of the above-mentioned voices of normality and of neuro-health professionalism. Furthermore, new voices are introduced. In the sentence, "Actually, I have to involve him", involvement is constructed as something that the professionals have to do. The word "actually" indicates a countering practice. ${ }^{6}$ This mean that the word constructs the following statement as a counterpoint to an expected discursive position. In this case, the sentence counters the expected position of a professional prerogative to choose to involve. This statement draws on a voice of systemic obligation. In this narrative, the voice of systemic obligation is two-fold. The voice asserts its dominance by defining involvement as both a moral obligation "I sometimes have a moral struggle" and a legal obligation "if I were to follow the law". These two powerful discursive resources align with the voice of normality in synchronic interplay. They co-create an underlying narrative of the right professional choice, which caters to and fits the normal patient. This constructs the main storyline in this narrative as a counter narrative that outlines the best professional choice for the abnormal patient. In this main storyline, involvement is ascribed meaning as a systemic practice that demands certain cognitive abilities. The sentence "that it doesn't work because he has a memory like a sieve" articulates a voice of neuro-health professionalism. The voice of neuro-health professionalism draws on an understanding of memory impairment as an obstacle to participation in a systemic involvement process. This constructs involvement as a practice that requires memory and the patient as someone who is not capable. In this context, memory exemplifies the ability to participate in a process over time. The inability to remember makes it difficult to maintain continuity in the rehabilitation process rooted in the patient's wishes and goals. The narrative constructs involvement as a process that is inaccessible for a person with cognitive impairments effecting their memory and their ability to communicate coherently. This construction of an inaccessible process creates the foundation for an alternative practice. In this case, the alternative becomes to involve the mother and 
consequently push the patient "more and more onto the sideline". This alternative is made available by a professional position of being the patients' advocate in the system - "to make the system work for him". This position is created in an alignment between the voice of neurohealth professionalism and a new voice of patient-centred care. The professional position draws on the voice of neuro-health professionalism to construct an inaccessible process of involvement. The voice of patient-centred care then disclaims the systemic obligation by reorienting the deviating action towards the patient's benefits - "to benefit his case and to benefit his situation". The message of the professional narrative becomes that which is best for the patient is not always the system's way of practising involvement.

The analysis addresses the professional experience of a discrepancy between systemic practices and patients' benefits. This is illustrated in the depiction of involvement as a demanding process that becomes exclusionary. The turn towards patient-centred care in the healthcare system has fostered the systemic translation of concepts like involvement and participation into professional practices. The analysis questions if the situated practices are able to accommodate all types of patients by showing how involvement is constructed around the presumption of a cognitively capable patient. The analysis also shows a duality in the professional decision-making which has to navigate two conflicting orientations: an orientation towards the legal and correct action and another towards the needs and capability of the patient.

\section{Meeting with or without the patient}

The following excerpt is a professional narrative about how the process of involvement unfolds during a recovery process. The narrative follows the recovery process of the young man with a severe traumatic injury to the brain. The narrative describes the professional challenge of practising involvement in such a process. The narrative paints a critical picture of how involvement is enacted in the professional practice and outlines the professional doubts about the process. In this narrative, the practice of involvement becomes an opposite to the professional assessment of the situation:

Amalie (municipality): "And where I've faced the challenge in this process of how do I get this totally injured citizen involved in any way? At first, he is not conscious. Then he wakes up and becomes a little more aware. He joins in the meetings. He is sitting there. We are addressing him when we say something even though it is actually directed to the professionals. So the situation is a little forced. But at the same time we all agree that it's really important that he is there because it's all about him and his life. We always notice that at some point during the meetings he gets really tired. And he starts feeling unwell. And he does not re- ally hear what happens and uhh...Even though we talk to him and ask him questions, then...At first it's not...It's more because we have to. Throughout the rehabilitation process, he becomes more and more aware and starts being able to communicate with expressions of agreement or disagreement. And we keep addressing him and asking him questions at the meetings and he comes up with some form of answer. When he listens during the meetings, he participates by expressing if he finds it good or bad or something else. The main involvement is directed at his relatives, his parents. It's with them we have a dialogue about what's going to or has to happen for this boy. Because at the meetings it's really hard to ask him, would you like to live at home? There are often up to fifteen people sitting around the table. And then he's hungry and he's thirsty. And do we get an answer we can count on? Of course, there is also a legal guardian in place, so of course there are some others who have to be involved in the decision. But I've often thought, is it the right thing to involve him in the meetings? And there was actually a meeting where he did not participate. Where the roles were completely different. The parents acted completely differently. They said some things they hadn't said previously. Which they would not say when he was there. Which was really important for the process. And gave us insight into his state and progression." (Quote from workshop 1)

The narrator starts by posing her own question of how to involve. This is a dialogically expansive practice that indicates an openness towards other dialogic alternatives to involving. Though the question is expansive towards the practice of involvement it is hinged on two fixed characters - the totally injured patient and the professional involver. The question "how do I get this totally injured citizen involved" constructs a perspective of involvement as process produced by the active professional and challenged by the passive patient. This constructs the patient with little or no agency and pinpoints the challenge of involvement as lying in the patient's inability to take on an active role. The construction of these roles in the question draws on the voice of patient-centered care as a backdrop. In the healthcare system's turn towards patient-centered care, the active patient role and the involving professional are central characters in producing better quality in healthcare. ${ }^{19}$ In this light, the question is asked in alignment with the voice of patient-centred care. It does not question whether or not to involve but is dialogically expansive towards a new perspective on how to involve.

The question is followed by a procedural description of the young man's progression from unconscious to aware to expressive. "At first, he is not conscious. Then he wakes up and becomes a little more aware. He joins in the meetings". His graduation to aware places him in the 
arena of the systemic practice of involvement, which is centered on participation in meetings. "He is sitting there. We are addressing him when we say something even though it is actually directed to the professionals. So the situation is a little forced". When the patient cannot participate on the premise of conversational interaction in the meeting, the situation becomes forced. In this section, the meeting is constructed as the setting for involvement and the process of involvement is bound to the conversational exchange and relational engagement performed in the meeting. This construction of involvement is informed by the voice of systemic practice that naturalizes this way of practising involvement. ${ }^{6}$ This construct the meeting as a given setting for a given relational exchange. In the narrative, this is merely a part of the procedural description and is not questioned. The voice of systemic practice aligns with the voice of patient-centred care in constructing the setting and practices as important by anchoring their legitimacy in patient-centredness - "we all agree that it's really important that he is there because it's all about him and his life".

The challenge arises as the patient is not able to engage in the relational exchange in the settings. In the sentence "during the meetings he gets really tired. And he starts feeling unwell. And he does not really hear what happens" it becomes evident that physical presence is not enough to fully perform participation in the institutionalized involvement practice. The participatory performance also entails listening and being alert. The patient is constructed as present but passive. Simultaneously the active professional involvers are demonstrated in wordings like "We always notice" and "we talk to him and ask him questions". In the interaction between the passive, present patient and the active involver, the involvement practice is enacted "because we have to". This reduction of involvement to a one-way communication loses the legitimacy formed in the alignment with the voice of patient-centred care. Instead, its legitimacy is rooted in the voice of systemic obligation (as described in relation to the previous empirical example).

As the patient's recovery progresses so does his participatory abilities. "Throughout the rehabilitation process, he becomes more and more aware and starts being able to communicate with expressions of agreement or disagreement". Communicative skills open up the possibility of confirming or negating decisions with the patient - "he participates by expressing if he finds it good or bad or something else". However, even though he can now answer, his participatory contribution to the involvement process is not fully valid. He still lacks the ability to engage in "a dialogue about what's going to or has to happen" and to be fully involved he has to be able to postpone bodily needs - "And then he's hungry and he's thirsty". The patient is constructed as a contributor but his contribution is not equal to the professionals or the parents - "do we get an answer we can count on?"
"But I've often thought, is it the right thing to involve him in the meetings?" The passive patient role becomes a challenging figure in the narrative because the involvement practice is a means to an end. The meetings require participation enacted through presence, awareness and dialogue to co-construct knowledge that holds legitimacy in the institutionalized rehabilitation process. This translates into specific knowledge forms that function as valid components in such a task. "Because at the meetings it's really hard to ask him, would you like to live at home?" The question is oriented towards his future needs and is focused on uncovering his preferences for services provided in the systemic context.

The question also speaks to the relational boundaries constructed in the meeting between all parties. In this case, a boundary may be that the young man will not to express a desire to live elsewhere as it could be hurtful to his parents and vice versa. "And there was actually a meeting where he did not participate. Where the roles were completely different. The parents acted completely differently. They said some things they hadn't said previously. Which they would not say when he was there. Which was really important for the process. And gave us insight into his state and progression." This final part of the narrative is dialogically expansive by entertaining an alternative discursive perspective. The question of his involvement in the meeting marks the discursive counterpoint. What follows is a narrative within the narrative. In the alter-narrative, the involvement practice that solely focus on patient-centredness as the presence of the patient is challenged by an alignment between the voice of systemic practice and the voice of neuro-health professionalism. These voices form a professional perspective on how meaningful meetings can be constructed by un-involving the patient. This alternative practice is legitimized by reconstructing the relational boundaries that hinder the generation of knowledge that holds value in the professional involvement practice. This is done by connecting the "meeting where he did not participate" to the altered behavior "Where the roles were completely different". This reframes the meeting as meaningful. However, the condition is an altered composition of people. By using terms like "his state and progression" the voice of neurohealth professionalism underscores the value of the altered behavior and thereby the meeting as a meaningful systemic practice without the presence of the patient.

The analysis shows how the concept of involvement is infused by the voice of patient-centred care and is therefore presumed to create better healthcare. In this context, better healthcare can be translated into progression in recovery through a coordinated rehabilitation effort. ${ }^{41}$ In this narrative, involvement loses its professional value when it cannot produce knowledge that can translate into the rehabilitation process. Participation is in this case only valued if it aligns with the purpose of producing procedural progression. In the narrative, the meeting is the arena for 
the relational exchange that produces progression towards better physical and mental recovery through rehabilitation efforts. The meaningful meeting and involvement practice is from a professional perspective anchored in progression and a temporal orientation towards the future process. The knowledge form the patients has access to in the encounter is depicted as anchored bodily and in the moment. This construction of involvement as a procedural tool of progression annuls the patient's knowledge form and it leaves the professional in a dilemma between practising involvement focusing on the patient or on the process. Both constructions of involvement draw on the broader discursive resource of patient-centred care. This institutionalized perspective naturalizes the concept of involvement as a given means to produce better healthcare for the patient.

\section{Discussion and Conclusions}

In this paper, I have examined how the interplay of different voices ascribe particular meanings to situated practices of involvement and forms identities tied to professional involvement practices in neurorehabilitation. The professionals construct and reconstruct involvement practices in interaction with patients who suffer the diverse effects of acquired brain injuries. My analysis shows that involvement presupposes patient participation. It also shows how the enactment of participation requires certain cognitive resources to be fully recognized and accepted. This particular patient group presents a challenge as brain damage can have the effect of impairing or altering normal cognitive functions. ${ }^{20,22,25}$

This study contributes to the study of patient-centred healthcare and dialogical health research with a specific focus regarding the professional perspective on patient involvement with a complex group of patients. By inquiring into the dialogic tensions that characterize involvement in professional narratives, the analysis shows how different voices construct and delimit different forms of action and reflection with respect to the enactment of involvement. In the narratives, the voice of patient-centred care is used both to ascribe meaning to institutionalized practices of involvement, but also to legitimize the actions and perspectives that deviate from the institutionalized norms of involvement. This is in line with the ambiguity that previous studies have described. ${ }^{3-5}$ In this study I highlight how the underlying demands of involvement are animated as a patient-centred practice. My analysis shows how involvement can be nothing less than a meaningful meeting where procedural goals are met. One narrative speaks of engaging with the patient as an alternative involvement technique. ${ }^{20}$ This engagement does not measure up to the ideal of involvement. This then leads to the health professionals' reorientation towards the next of kin as they can fulfil the requirement of participation. The patients are constructed and positioned as incapable (disabled). ${ }^{24}$ This points to an involvement practice where subjective expe- rience is secondary to the goals of objective process. ${ }^{4,17}$ Even though the voice of neuro-health professionalism has the language to describe and ascribe another meaning to the patient, the voice does not challenge the dominant view of patient-centred care practices. The paper is my empirical contribution to the studies that advocate how the patient-centred perspective is merged with existing perspectives in healthcare institutions. ${ }^{18}$ It also points to this blending of voices as a strong discursive resource that in some cases hinders a more individualized practice of involvement at the point of care delivery.

In this paper, I find that the health professionals navigate a tension between the ideal of what patient-involvement should be and how involvement is practised in the institutional setting. The study helps illustrates how some practices are constraining or problematic when involving patients suffering the diverse effects of traumatic brain injury. Nevertheless, the narratives also hold an optimism in how the health professional try their best to balance both the perspective of the patient, the clinical outcomes and the institutional values. In the narratives, the voice of systemic obligation functions as both a detachment mechanism and it holds the potential for defiance in the construction of meaning. It holds a recognition that some of the systemic practices are not applicable in the everyday care delivery between the patient and the professional. In the narratives, the voice animates the onset of opposition to the institutional logic of patient involvement being the only correct strategy in creating the best rehabilitation process. I do not see this as the professionals opposing involvement as a strategy but opposing the consolidated practices that are conceptualized as involvement. The consolidated practices being the relational exchange situated in a meeting and procedural knowledge forms that are legitimate in this space. ${ }^{3,17}$ The narratives describe deviant institutional behaviour that also has the patient-centred perspective in play. Confined to the systemic context the alternative becomes to not involve because the dominant practices are naturalized and therefore not in question.

With the findings of this paper I propose that the relational nature of patient-centred care becomes the focus of co-producing situated involvement measures. This recognizes the need for reconciling different knowledge forms and letting the tension evolve new perspectives that fuse both the patient and the health professionals agenda. ${ }^{3}$ In practice, this vision is built on an institutional recognition of personal knowledge as the key to generating quality for the individual patient in healthcare and not as a mean to objectify healthcare delivery. In the paper I illuminate how institutional voices make such situated practice unavailable in the relational negotiation of the health professional. The only available alternative is to not involve the patient. This questions the flexibility of the current practices. It also points to a need for reflexive spaces where it is possible to question the naturalized practices and systemic adaptions of involvement. A characteristic of the narratives presented 
is that they came from a place of doubt or wonder. ${ }^{6}$ These are both communicative indications of a dialogical struggle. The doubt-driven stories produced tension filled and dialogically expansive arenas for reflexive co-inquiry. In this paper I put forward the notion that a practical starting point for developing new and person-centred involvement practices could be to co-reflect on the professional doubts that form within care delivery.

\section{References}

1. Miles A, Mezzich J. The care of the patient and the soul of the clinic: person-centered medicine as an emergent model of modern clinical practice. Int J Pers Cent Med 2011;1:207-22.

2. Starfield B. Is patient-centered care the same as person-focused care? Perm J 2011;15:63-9.

3. Mjølstad BP, Luise Kirkengen A, Getz L, Hetlevik I. Standardization meets stories: Contrasting perspectives on the needs of frail individuals at a rehabilitation unit. Int J Qual Stud Health Well-being 2013;8.

4. Lord L, Gale N. Subjective experience or objective process: understanding the gap between values and practice for involving patients in designing patient-centred care. J Health Organ Manag 2014;28:714-30.

5. Leplege A, Gzil F, Cammelli M, et al. Person-centredness: Conceptual and historical perspectives. Disabil Rehabil 2007;29:1555-65.

6. Baxter LA. Voicing relationships, a dialogic perspective. Los Angeles, CA: Sage; 2011.

7. Baxter LA, Suter EA, Thomas LJ, Seurer LM. The dialogic construction of "adoption" in online foster adoption narrative...: EBSCOhost. J Fam Commun 2015;15:193-213.

8. Phillips LJ. The promise of dialogue, the dialogic turn in the production and communication of knowledge. Amsterdam: John Benjamins; 2011.

9. Renedo A, Marston C. Developing patient-centred care: an ethnographic study of patient perceptions and influence on quality improvement. BMC Health Serv Res 2015;15:122.

10. Pedersen AR. The role of patient narratives in healthcare innovation: supporting translation and meaning making. J Health Organ Manag 2016;30:244-57.

11. Borgermans L, Marchal Y, Busetto L, et al. How to improve integrated care for people with chronic conditions: key findings from EU FP-7 Project INTEGRATE and beyond. Int J Integr Care 2017;17.

12. Borgermans L, Devroey D. A Policy Guide on Integrated Care (PGIC): Lessons Learned from EU Project INTEGRATE and Beyond. Int J Integr Care 2017;17.

13. Vrangbaek K. Patient involvement in Danish health care. J Health Organ Manag 2015;29:611-24.

14. Dent M, Pahor M. Patient involvement in Europe - a comparative framework. J Health Organ Manag 2015;29:546-55.

15. Pedersen KZ, Kjær P. "The new patient": the emergence of a political persona. Int J Public Sect Manag 2017;30:85-98.

16. Apker J. Communication in health organizations. Cambridge: Polity Press; 2012. 271 p.

17. Abreu BC, Zhang L, Seale G, et al. Brain Injury Interdisciplinary meetings: investigating the collaboration between persons with brain injury and treatment teams. 2002; Available from: http://www.tandfonline.com/action/journalInformation?journalCode=ibij20 Accessed 2018 Dec 10.
18. Ledderer L. Bringing about change in patient-centred preventive care. Int J Public Sect Manag 2010;23:403-12.

19. McDermott AM, Pedersen AR. Conceptions of patients and their roles in healthcare. In: M McDermott, AR Pedersen, eds. J Health Organ Manag 2016;30:194-206.

20. Lawrence M, Kinn S. Defining and measuring patient-centred care: An example from a mixed-methods systematic review of the stroke literature. Heal Expect 2012;15: 295-326.

21. Alby F, Fatigante M, Zucchermaglio C. Managing risk and patient involvement in choosing treatment for cancer: an analysis of two communication practices. Sociol Health Illn 2017;39:1427-47.

22. Rosewilliam S, Roskell CA, Pandyan A. A systematic review and synthesis of the quantitative and qualitative evidence behind patient-centred goal setting in stroke rehabilitation. Clin Rehabil 2011;25:501-14.

23. Falk K, Ung EJ, Östman M. Health-care encounters create both discontinuity and continuity in daily life when living with chronic heart failure - A grounded theory study. Int J Qual Stud Health Well-being 2015;10.

24. Marks D. Models of disability. Disabil Rehabil 1997; 19:85-91.

25. Kontos PC, Miller K-L, Gilbert JE, et al. Improving Clientcentered brain injury rehabilitation through research-based theater. Qual Health Res 2012;22:1612-32.

26. Pors AS. Constructions of the patient in healthcare communications: six patient figures. J Health Organ Manag 2016;30:279-98.

27. Frank AW. Just listening: Narrative and deep illness. Fam Syst Heal 1998;16:197-212.

28. Humle DM, Pedersen AR. Fragmented work stories: Developing an antenarrative approach by discontinuity, tensions and editing. Manag Learn 2015;46:582-97.

29. Davenport NHM. Medical residents' use of narrative templates in storytelling and diagnosis. Soc Sci Med 2011;73:873.

30. Charon R. Narrative medicine: attention, representation, affiliation. Narrative 2005;13:261-70.

31. Overcash JA. Narrative research: a review of methodology and relevance to clinical practice. Crit Rev Oncol Hematol 2003;48:179-84.

32. Bakhtin MM. Problems of Dostoevsky's poetics. Bakhtin In: Mikhail Mikhailovich MM, Emerson C, (Firm) P, eds. Minneapolis: University of Minnesota Press; 1984.

33. Bakhtin MM. Dialogic imagination: four essays. Holquist M, ed. Austin: Austin, TX, USA: University of Texas Press; 1981.

34. Balbale SN, Turcios S, LaVela SL. Health care employee perceptions of patient-centered care. Qual Health Res 2015;25:417-25.

35. Phillips L, Napan K. What's in the "co"? Tending the tensions in co-creative inquiry in social work education. Int $\mathrm{J}$ Qual Stud Educ 2016;29:827-44.

36. Soffer M, Chew F. Framing disability among young adults with disabilities and non-disabled young adults: an exploratory study. Disabil Rehabil 2015;37:171-8.

37. Kristiansen M, Bloch-Poulsen J. Participation as enactment of power in dialogic organisational action research. Reflections on Conflicting Interests and Actionability Zur Verfügung gestellt in Kooperation mit/provided in cooperation with. Int J Action Res 2011;7:347-80.

38. Charon R. At the membranes of care: stories in narrative medicine. Acad Med 2012;87:342-7. 
39. Barge JK, Little M. Dialogical wisdom, communicative practice, and organizational life. Commun Theory 2002;12: 375-97.

40. Delmar C. "Generalizability" as recognition: reflections on a foundational problem in qualitative research. Qual Stud 2010;1:115-28.
41. Sundhedsstyrelsen. Kommissorium for servicetjek af genoptrænings- og rehabiliteringsindsatserne for personer med erhvervet hjerneskade. 2017;2014. Available from: http:// www.sum.dk/Aktuelt/Nyheder/Kommunale_sundhedsopgaver/2017/Februar/ /media/Filer - dokumenter/ Kom-servicetjek-hjerneskadeomraadet.ashxstudie 